\title{
BRAKING DECELERATION MEASUREMENT USING THE VIDEO ANALYSIS OF MOTIONS BY SW TRACKER
}

\author{
Ján Ondruš ${ }^{1}$, Peter Hockicko ${ }^{2}$ \\ ${ }^{1}$ University of Zilina in Zilina, Faculty of Operation and Economics of Transport and Communications, \\ Department of Road and Urban Transport \\ Univerzitná 8251/1, SK-010 26 Žilina, Slovak Republic \\ Phone: +421 415133 526,e-mail: jan.ondrus@fpedas.uniza.sk \\ ${ }^{2}$ University of Zilina in Zilina, Faculty of Electrical Engineering, Department of Physics \\ Univerzitná 8251/1, SK-010 26 Žilina, Slovak Republic \\ Phone: +421 415132 364, e-mail: peter.hockicko@fel.uniza.sk
}

\begin{abstract}
This contribution deals with the issue of car braking, particularly with the one of M1 category. Braking deceleration measurement of the vehicle Mazda 3 MPS was carried out by the declerograph XL Meter ${ }^{\mathrm{TM}}$ Pro. The main aim of the contribution is to perform comparison of the process of braking deceleration between the decelograph and the new alternative method of video analysis and to subsequently examine these processes. The test took place at the Rosina airfield, the airstrip in a small village nearby the town of Žilina. The last part of this paper presents the results, evlauation and comparison of the measurements carried out.
\end{abstract}

Keywords: braking deceleration, braking time, braking distance, analysis, decelograph XL Meter ${ }^{\mathrm{TM}}$ Pro, SW Tracker

\section{Introduction}

Intensive vehicle braking is usually an essential and defensive drivers' reaction in order to avoid an accident. Indeed, the detection of the real value reached during intense vehicle braking is one of the key factors in the process of accident investigation. Current statutory requirements for approving technical roadworthiness of the vehicles, define the basic requirements for braking system construction for individual vehicle categories. (Hockicko, P., Ondruš, J., 2012)

\section{Test vehicle}

Mazda 3 MPS 2,3 MZR DISI model year 03/2011 was used as the test vehicle (Fig. 1). It was loaded with one person (a driver) at the moment of the tests. The vehicles' technical data is shown in Table 1; the tires of Pirelli brand were of 205/50/R17 93 dimension with the $5.1 \mathrm{~mm}$ tread depth of the front tires and $5.7 \mathrm{~mm}$ of the rear ones.

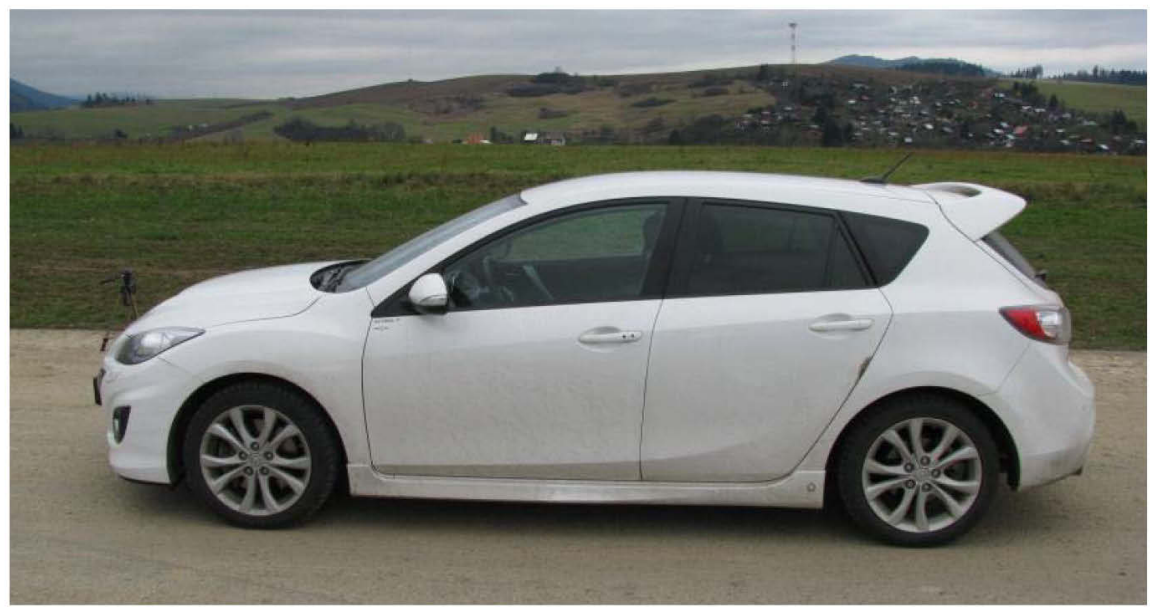

Figure 1. Mazda 3 MPS 2,3 MZR DISI 
Table 1. Technical data

\begin{tabular}{|l|l|}
\hline Identification data: & \\
\hline Country of origin: & Japan \\
\hline Make: & Mazda \\
\hline Model: & 3 (2nd-gen. phase-I MPS MazdaSpeed) \\
\hline Body style: & Hatchback \\
\hline Doors: & 5 \\
\hline Traction: & FWD (front-wheel drive) \\
\hline
\end{tabular}

\begin{tabular}{|l|l|}
\hline Weights: & \\
\hline $\begin{array}{l}\text { Curb weight (without a } \\
\text { driver): }\end{array}$ & $1385 \mathrm{~kg}$ \\
\hline Gross vehicle weight: & $1925 \mathrm{~kg}$ \\
\hline Payload: & $540 \mathrm{~kg}$ \\
\hline Towing weight: & \\
\hline Unbraked: & $550 \mathrm{~kg}$ \\
\hline Braked: & $1300 \mathrm{~kg}$ \\
\hline
\end{tabular}

\begin{tabular}{|l|l|}
\hline Powertrain: & \\
\hline Engine: & MZR DISI 2,3L Turbo \\
\hline Engine type: & Inline, 4-cylinder, DOHC Turbo petrol \\
\hline Displacement: & $2261 \mathrm{~cm} 3$ \\
\hline Bore x Stroke: & $87,5 \times 94,0$ \\
\hline Compression ratio: & $9,5: 1$ \\
\hline Valves: & 4 per cylinder \\
\hline Max power: & $260 \mathrm{HP}(190 \mathrm{~kW})$ at $5500 \mathrm{rpm}$ \\
\hline Max torque: & $380 \mathrm{Nm}(280 \mathrm{lb}-\mathrm{ft})$ at $3000 \mathrm{rpm}$ \\
\hline Top speed: & $250 \mathrm{~km} / \mathrm{h}$ \\
\hline Fuel consumption: & $9,61 / 100 \mathrm{~km}$ \\
\hline Fuel type: & Unleaded $98 \mathrm{RON}$ \\
\hline Emission control system: & 3 -way catalytic converter \\
\hline Emission ranking: & Euro Stage V \\
\hline Transmission: & 6 -speed manual \\
\hline Powertrain: & Front engine, front-wheel drive \\
\hline
\end{tabular}

\begin{tabular}{|l|l|}
\hline Weights: & \\
\hline $\begin{array}{l}\text { Curb weight (without a } \\
\text { driver): }\end{array}$ & $1385 \mathrm{~kg}$ \\
\hline Gross vehicle weight: & $1925 \mathrm{~kg}$ \\
\hline Payload: & $540 \mathrm{~kg}$ \\
\hline Towing weight: & \\
\hline Unbraked: & $550 \mathrm{~kg}$ \\
\hline Braked: & $1300 \mathrm{~kg}$ \\
\hline
\end{tabular}

\begin{tabular}{|l|l|}
\hline Acceleration: & \\
\hline $0-100 \mathrm{~km} / \mathrm{h}:$ & $6,1 \mathrm{~s}$ \\
\hline $50-100 \mathrm{~km} / \mathrm{h}$ in 3 -rd gear: & $4,2 \mathrm{~s}$ \\
\hline $80-120 \mathrm{~km} / \mathrm{h}$ in 5 -th gear: & $5,4 \mathrm{~s}$ \\
\hline
\end{tabular}

\begin{tabular}{|l|l|}
\hline Suspension: & \\
\hline Front suspension: & $\begin{array}{l}\text { MacPherson } \\
\text { independent struts }\end{array}$ \\
\hline Rear suspension: & Independent multi-link \\
\hline
\end{tabular}

Source: (http://www.automobile-catalog.com/auta_details1.php, 2014)

The safety systems effecting the braking force installed in the vehicle include: ABS (Anti-lock Braking System), EBD (Electronic Brakeforce Distribution), EBA (Electronic Brake Assist), DSC (Dynamic Stability Control), TCS (Traction Control System), LSD (Limited Slip Differencial), active seat belt tensioners, EBS (Emergency Brake-light System).

\section{Measurement devices}

\subsection{Decelograpf - Inventure XL Meter $^{\mathrm{TM}}$ Pro}

Measurement device XL Meter ${ }^{\mathrm{TM}}$ Pro of the 3rd generation was used for measuring (Fig. 2). It is a universal accelero/decelerometer with the alphanumercid LCD display. It serves to measure and evaluate vehicle acceleration and the state of its service brakes; it's easy to operate as it uses only 3 buttons placed at the top of the device box, each of them being of a different colour (black, green, red) and therefore of a different function.

The device is powered by a battery but it can also be connected via an external source. From the technical point of view, it consists of three main parts: electronics, a vacuum suction cupule and an articulated arm which allows customizable mounting. XL Meter ${ }^{\mathrm{TM}}$ Pro is easy to attach to the desired location on the surface of the vehicle windshield or any other smooth surface and it can be fixed to the surface by turning the lever of the vacuum suction cupule. The device is built-in into an aluminium box which is purpose-designed to provide easy controlability and installation. The articulated arm allows zero 
point calibration while being installed on the vehicle windshield by means of the vacuum suction cupule. (http://www.inventure.hu/xl_meter_en, 2014)

There are two slots at the back panel; nine-pin D-SUB connector RS-232 allows connection with the computer and it may also be used to connect the brake pedal sensor as well as output signal control and the round slot is used to power the device from the external source (CC-in adapter), (Handbook of XL Meter ${ }^{\mathrm{TM}}$ Pro, 2011).

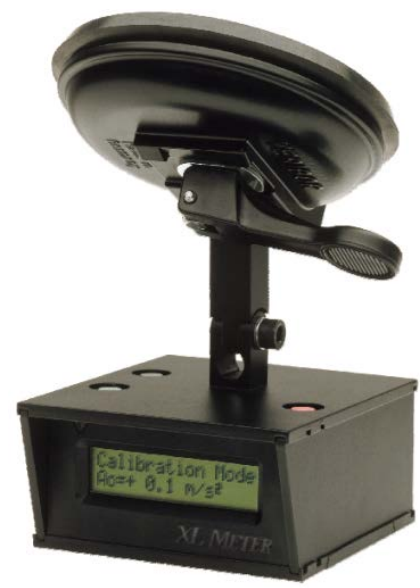

Figure 2. XL Meter ${ }^{\mathrm{TM}}$ Pro (http://www.inventure.hu/upload/downloads/XLMPLFEN22.pdf, 2014)

The 14-bit measuring technology has been improved in the process of new HL Meter ${ }^{\mathrm{TM}}$ Pro development. Thanks to its increased storage capacity it is now possible to realise 8 measurements without the necessity to transfer data directly into a computer. The new functions of synchronisation and remote control enable easier and more comfortable usage. The modular architecture makes XL MeterTM Pro the ultimate device either for speed-up or brake performance tests. (http://www.inventure.hu/upload/downloads/XLMPLFEN22.pdf, 2014). Table 2 shows its basic specifications.

Table 2. Basic specifications

\begin{tabular}{|c|c|}
\hline Technical Data & Features \\
\hline 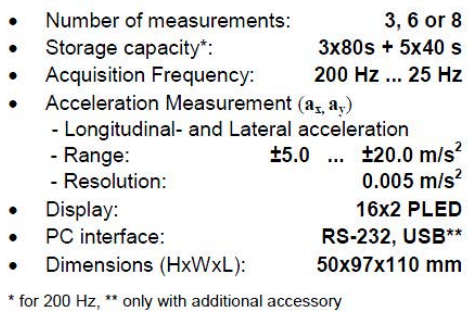 & $\begin{array}{l}\text { - } \quad \text { Measures Longitudinal- and Lateral acceleration } \\
\text { - } \quad \text { Brake fast, strong installation, easy handling } \\
\text { - } \quad \text { On the spot service brake performance evaluation } \\
\text { - On the spot acceleration performance evaluation } \\
\text { - } \quad \text { Modular system architecture } \\
\text { - } \quad \text { Selectable acceleration direction } \\
\text { - } \quad \text { Optional display language } \\
\text { - } 80 \text { hours continuous operation with one battery-set }\end{array}$ \\
\hline \multicolumn{2}{|l|}{ Applications } \\
\hline $\begin{array}{l}\text { - Service brake performance evaluation } \\
\text { - Retarder brake performance evaluation } \\
\text { - Tram brake performance evaluation } \\
\text { - Accident reconstruction } \\
\text { - Vehicle diagnostics measurement }\end{array}$ & 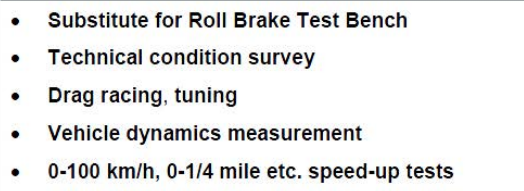 \\
\hline
\end{tabular}

Source: (http://www.inventure.hu/upload/downloads/XLMPLFEN22.pdf, 2014)

The electronic system of the device continuously records values of output signal voltage during the measurement, with the sampling rate of $200 \mathrm{~Hz}$, i.e. the values are measured and recorded every $5 \mathrm{~ms}$. There is an automatic off position recognition built-in in the device, so the precise zero point setting is not that necessary. The device records the course of acceleration within a span of 40 seconds from the moment of being turned on. After the measurement is over, the screen displays the value of mean fully developed deceleration (MFDD), the braking distance $\left(\mathrm{s}_{0}\right)$, the initial velocity $\left(\mathrm{v}_{0}\right)$, and the intensive braking time ( $\left.t_{b r}\right)$, (Rievaj et al., 2013). 
Mean fully developed deceleration (MFDD) is on the basis of norm EHK 13 calculated as the mean deceleration regarding the distances travelled in the interval from $\mathrm{v}_{\mathrm{b}}$ to $\mathrm{v}_{\mathrm{e}}$ in accordance with the formula (Hockicko, P., Ondruš, J., 2012). Individual parameters appearing in the formula can be also represented graphically (Fig. 3), (Kolla et al., 2014).

$$
M F D D=\frac{v_{b}{ }^{2}-v_{e}{ }^{2}}{25,92 \cdot\left(s_{e}-s_{b}\right)},
$$

where:

MFDD -mean fully development deceleration $\left[\mathrm{m} . \mathrm{s}^{-2}\right]$,

$\mathbf{v}_{\mathbf{0}}$ - initial vehicle speed $[\mathrm{km} / \mathrm{h}]$,

$\mathbf{v}_{\mathbf{b}}-$ vehicle speed at $0,8 \mathrm{v}_{\mathrm{o}}[\mathrm{km} / \mathrm{h}]$,

$\mathbf{v}_{\mathbf{e}}$ - vehicle speed at $0,1 \mathrm{v}_{\mathrm{o}}[\mathrm{km} / \mathrm{h}]$,

$\mathbf{s}_{\mathbf{b}}$ - distance travelled between $\mathrm{v}_{\mathrm{o}}$ a $\mathrm{v}_{\mathrm{b}}[\mathrm{m}]$,

$\mathbf{s}_{\mathrm{e}}$-distance travelled between $\mathrm{v}_{\mathrm{o}}$ a $\mathrm{v}_{\mathrm{e}}[\mathrm{m}]$

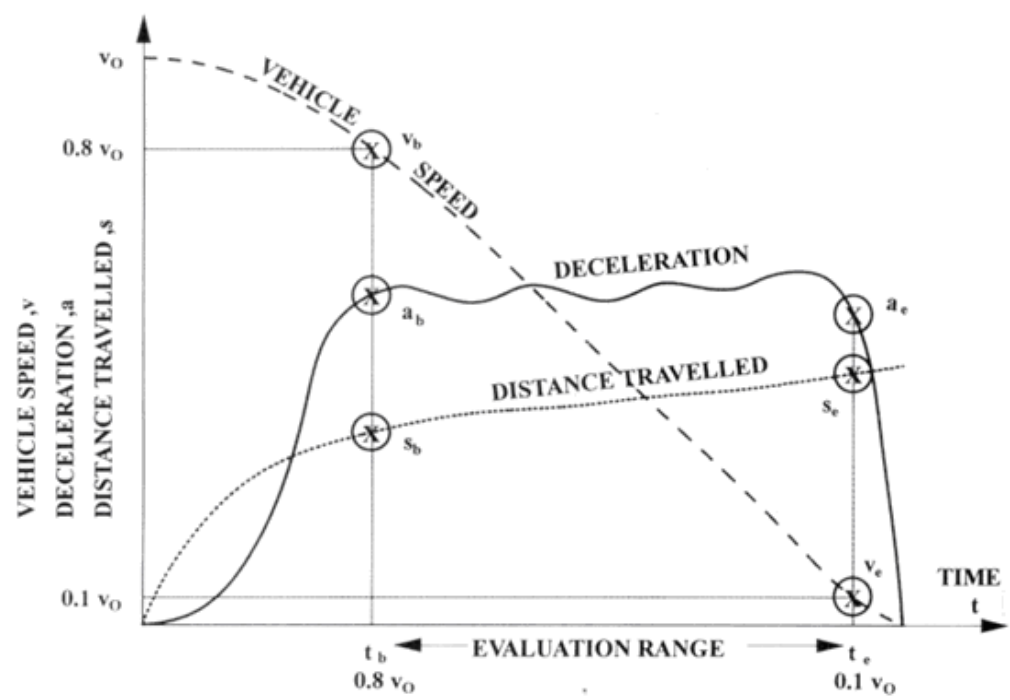

Figure 3. Dependence of vehicle speed, distance travelled and braking deceleration for the calculation of MFDD (Šarkan, B., 2013)

\subsection{Digital camera Casio Exilim EX-FH25}

Casio Exilim EX-FH25 digital high-speed camera was used for the measurement for videoanalysis purposes (Fig. 4). The camera combines a set of quick functions, such as high-speed serial picture recording that can take up to 30 9-pixel-pictures per seconds, three inch LCD, high-speed film recording that can take up to 1000 images per second, the innovative highly sensitive CMOS sensor for pictures with optimal exposure at 10.1 megapixels, powerful $26 \mathrm{~mm}$ wide-angle lens with 20x optical zoom. It also features slow motion view option that enables users to monitor the motion of an object in slow mode before picture capturing, (http://www.exilim.eu/euro/exilimhighspeed/exfh25/, 2014).

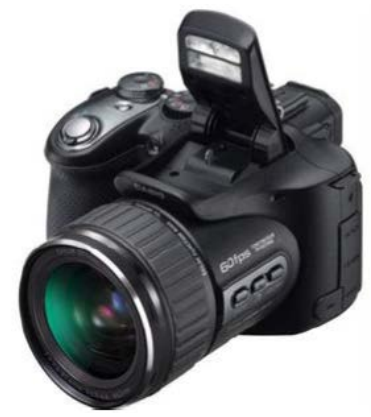

Figure 4. High-speed digital camera Casio Exilim EX-FH25 (http://www.exilim.eu/euro/exilimhighspeed/exfh25/, 2014) 
Measurement quality depends on the image width and the camera distribution. The acquisition frequency of camera was $30 \mathrm{~Hz}$. In order to have sufficiently distinctive contour and movement of the car, we could not place the camera too far. We decided to install it in such a manner that we had the space of $2.5 \mathrm{~m}$ in front of point B (Fig. 6). The braking started when the vehicle passed point B by its left side mirror. The program Tracker measured that the camera shooting width was of $50 \mathrm{~m}$ which was sufficient for the speed of $100 \mathrm{~km} / \mathrm{h}$. (Fig. 5). The problem arose at speed over $100 \mathrm{~km} / \mathrm{h}$ as the braking distance overshot the camera coverage. It is also necessary to take into account a certain error when applying the brakes at higher speeds. This error is brought about by a driver's inaccurate estimation of when point B is passed and so the brakes are to be applied.

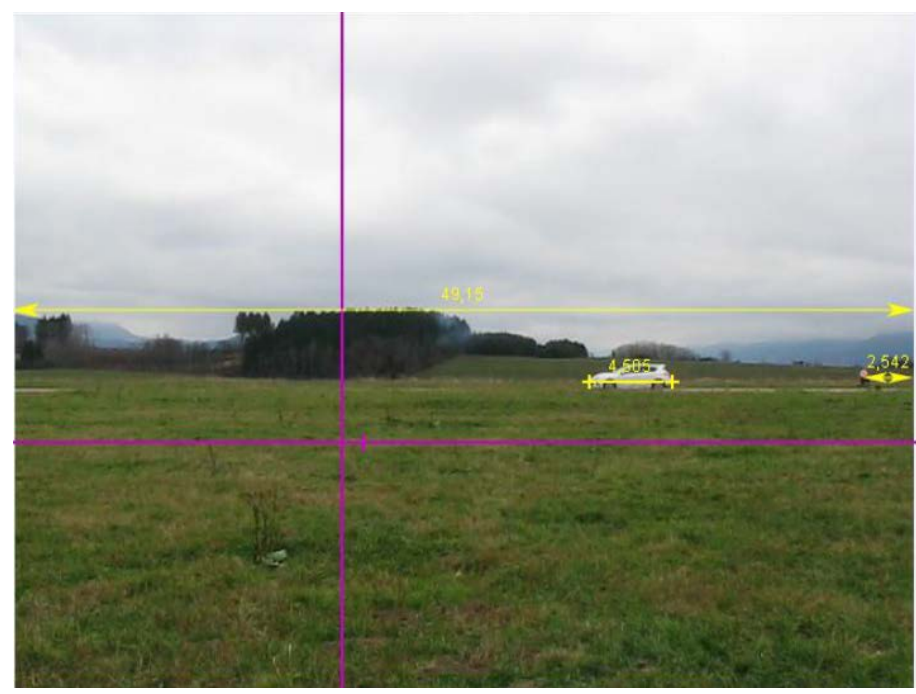

Figure 5. Camera coverage

\section{Measurement and measurement methods}

The experiment was carried out on 30 November 2013 at the Rosina airfield. The surface conditions were: dry asphalt runway with the estimated adhesion factor of range $0.80-0.90$ and the runway temperature was of $6{ }^{\circ} \mathrm{C}$. The temperature of ambient air was $3{ }^{\circ} \mathrm{C}$ with low speed wind so we could ignore its impact on the measurement. The length of the experimental track was approximately of $250 \mathrm{~m}$ (Fig. 6). Certain measurement inaccuracy was caused by the surface gratient estimated at $2 \%$.

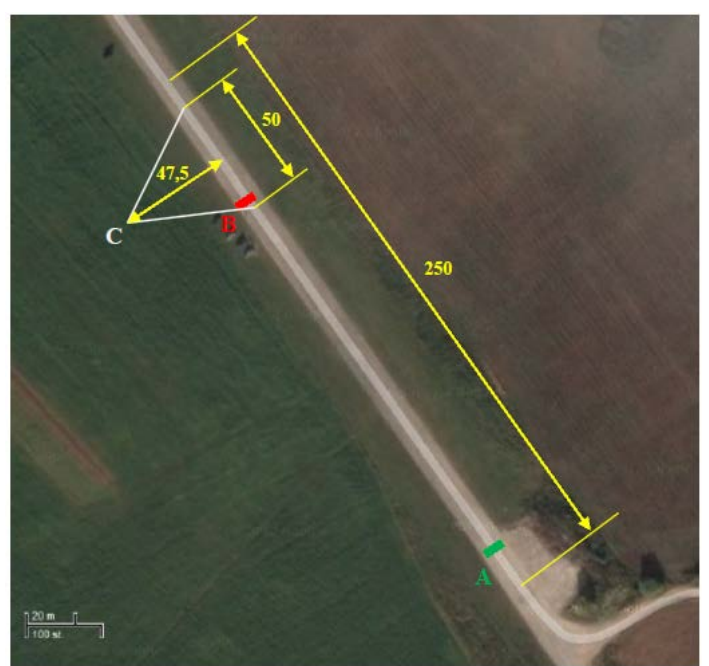

Figure 6. The experimental track

Measurement device XL Meter ${ }^{\mathrm{TM}}$ PRO was installed on the inside Mazda 3 MPS 2,3 MZR DISI windshield by means of the vacuum suction cupule (Fig. 7). 
The decelerograph was fixed by means of the vacuum suction cupule on the inside windshield during the measurement. The device was positioned in a way so that its measuring axis was parallel to the drive direction and so its controls were within reach of operation.

The device switches into calibration mode after being switched on and successful completion of the automatic system control. The mode then displays current value of measured acceleration. If a vehicle stands still on the horizontal surface, the displayed value is to be of $0 \mathrm{~m} . \mathrm{s}^{-2}$. Any deviation can be rectified by manipulating the devices' butt hinge so its measuring axis is in the closest possible horizontal position.

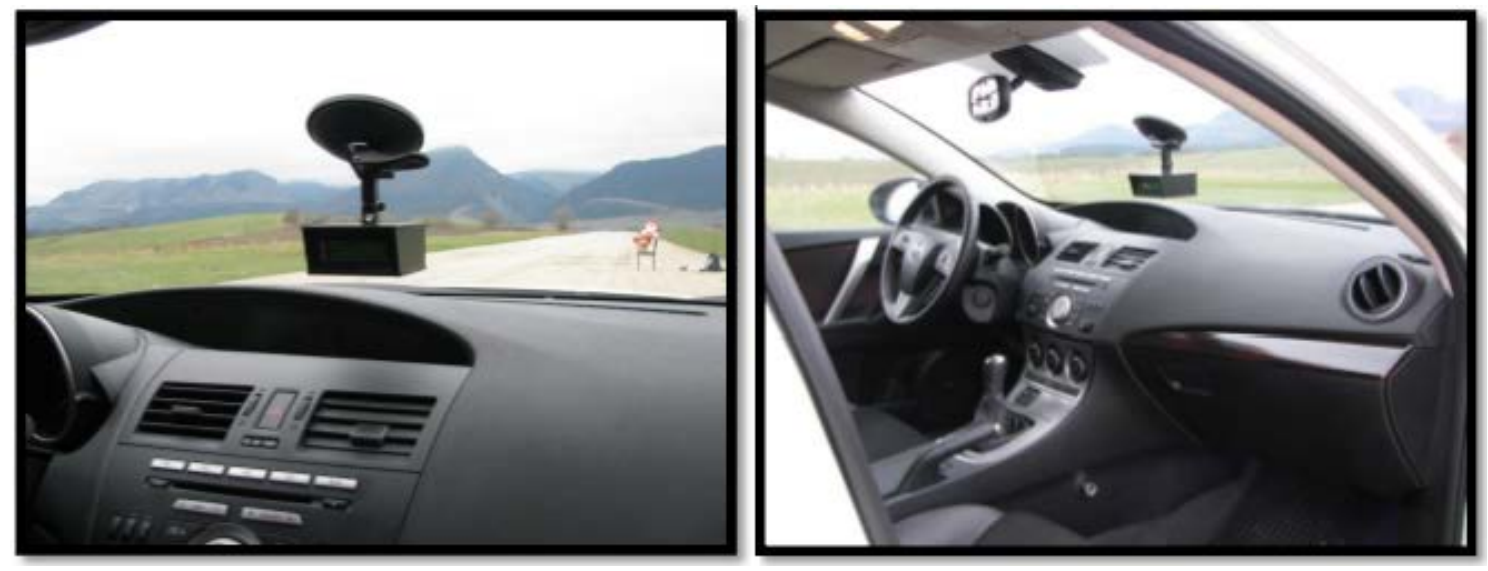

Figure 7. Location of XL Meter ${ }^{\mathrm{TM}}$ Pro in the vehicle

System sampling rate was set to $200 \mathrm{~Hz}$, i.e. we had 200 data per second available. Just before the start, it was necessary to launch XL Meter ${ }^{\mathrm{TM}}$ Pro measurment process and to signal the person operating the camera to start recording. The camera was placed at point $\mathrm{C}$ at the distance of $47.5 \mathrm{~m}$ and perpendicular to the braking distance. The test was recorded at the frequency of 30 frames per second. The target process to be observed was braking with the fully applied service brake while the vehicle was equipped with ABS. The driver set the vehicle in motion to the desired speed from point A. By activating speed limiter function we achieved the desired speed not to be exceeded. Then at the moment of the desired steady speed the driver violently pushed the service brake pedal when being at point B. Braking was being conducted until the vehicle reached zero speed.

All data were being recorded and were available in a complete file at the end of the experiment. It was necessary to stop data recording when the vehicle reached the zero speed by pushing the off button. The experiment measurement was repeated after a short break.

\section{Processing of measured data}

Obtained data were processed by the programes SW XL Vision ${ }^{\mathrm{TM}}$ Pro and SW Tracker.

\subsection{Vision ${ }^{\mathrm{TM}}$ Pro}

All data measured by XL Meter ${ }^{\mathrm{TM}}$ Pro can be saved and evaluated later offline. Individual data are stored in the permanent memory so they are accessible even after the device is off but unly until being rewritten. The device enables 8 different measurements to be stored in its memory. It is also possible to transfer all the recorded data into PC by means of serial RS-232 cable or by standard USB cable. Communication and transfer of the measured data between a PC and the XL Meter ${ }^{\mathrm{TM}}$ Pro device and its sequential evaluation is provided by the freeware XL Vision ${ }^{\mathrm{TM}}$ Pro (Fig. 8). Data transfer is available only in the calibration mode and in the display mode at the end of the display cycle.

XL Vision ${ }^{T M}$ Pro includes ever-increasing number of functions. The aim of the ever-increasing program facilities is to offer the professionals a full computer evaluation of accelerations and decelerations of different vehicles such as passenger cars, commercial vehicles, trucks, coaches, etc. The program also enables very easy documenation and archiving of measured data. Measurement results are possible to be printed in the form of measurement protocol which contains all the important data and information, (Handbook of XL Meter ${ }^{\mathrm{TM}}$ Pro, 2011). 

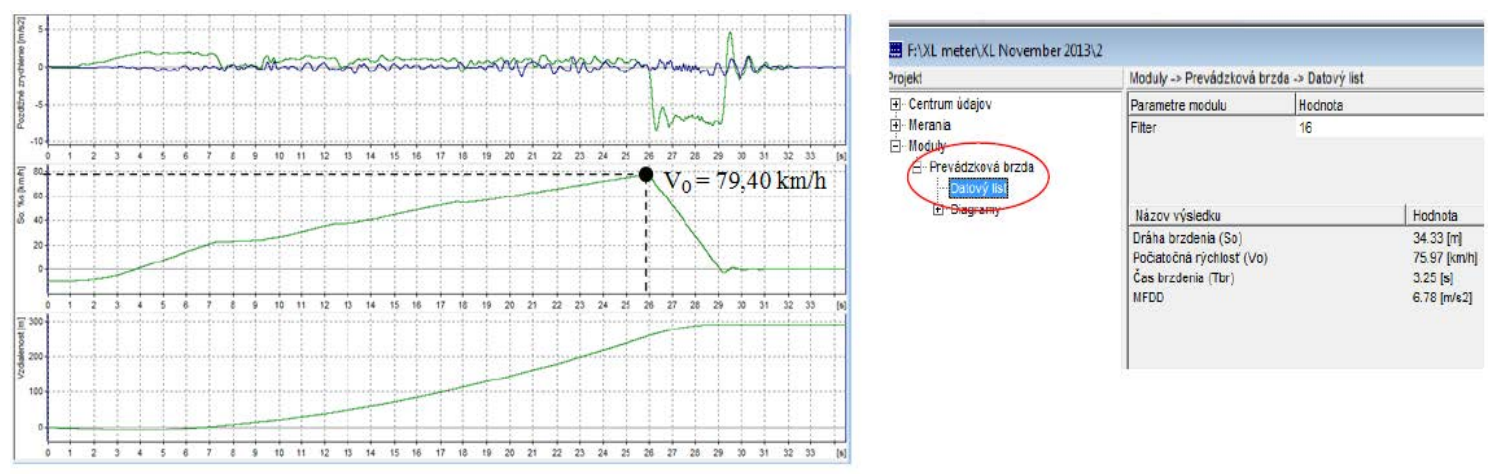

Figure 8. SW XL Vision ${ }^{\mathrm{TM}}$ Pro

\subsection{SW Tracker (version 4.8)}

The program Tracker is a free video analysis and modelling tool built on the Open Source Physics (OSP) Java framework. It is designed to be used in physics education. Tracker video modelling is a powerful new way to combine videos with computer modelling (Fig. 9).

\section{Tracker Features}

Tracking:

- Manual and automated object tracking with position, velocity and acceleration overlays and data.

- Center of mass tracks.

Modelling:

- Model Builder creates kinematic and dynamic models of point mass particles and two-body systems.

- Model overlays are automatically synchronized and scaled to the video for direct visual comparison with the real world.

Video:

- Free Xuggle video engine plays and records most formats (mov/avi/flv/mp4/wmv etc) on Windows/OSX/Linux.

- Video filters, including brightness/contrast, ghost trails, and deinterlace filters.

- Perspective filter corrects distortion when objects are photographed at an angle rather than straight-on.

- Radial distortion filter corrects distortion associated with fisheye lenses.

- Export Video wizard enables editing and transcoding videos, with or without overlay graphics, using Tracker itself.

- Video Properties dialog shows video dimensions, path, frame rate, frame count, more.

Data generation and analysis:

- Fixed or time-varying coordinate system scale, origin and tilt.

- Multiple calibration options: tape, stick, calibration points and/or offset origin.

- Switch easily to center of mass and other reference frames.

- Protractors and tape measures provide easy distance and angle measurements.

- Add editable text columns for comments or manually entered data.

- Data analysis tool includes powerful automatic and manual curve fitting.

Other:

- Full undo/redo with multiple steps.

- Page view displays html instructions or student notes.

- User preferences: GUI configuration, video engine, default language, font size, more, (http://www.cabrillo.edu/ dbrown/tracker, 2014). 

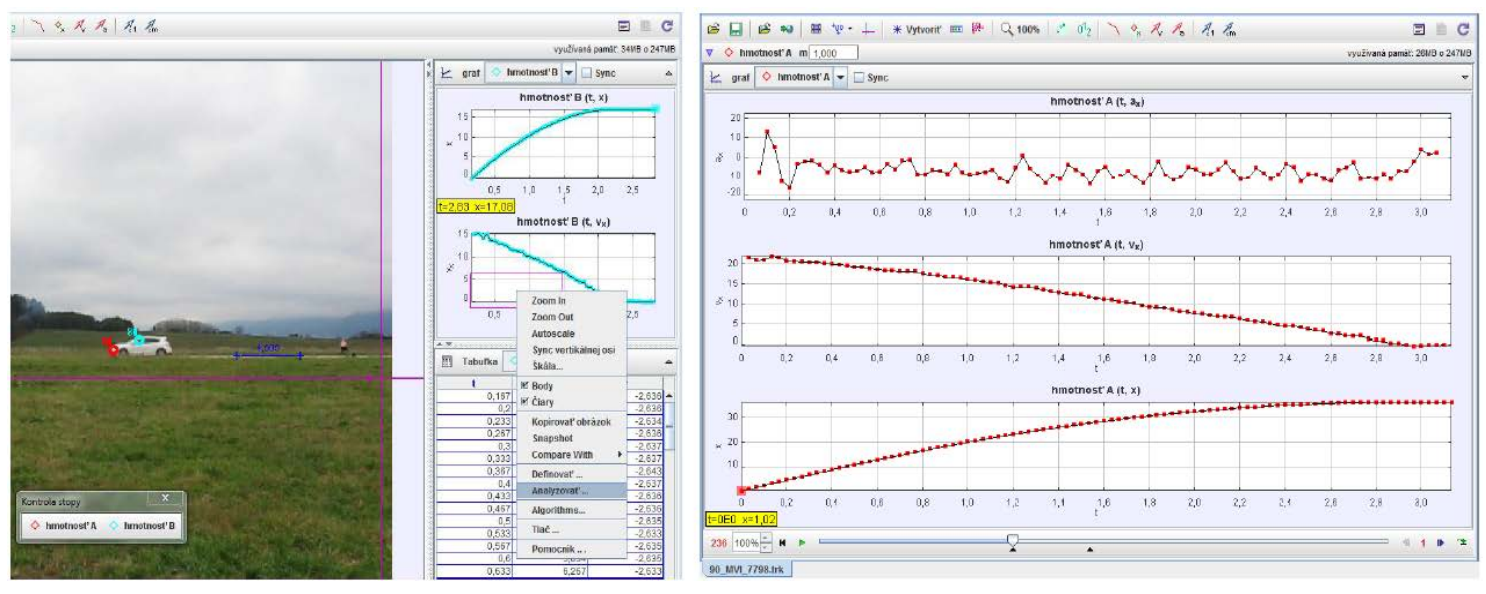

Figure 9. SW Tracker (ver. 4.8.)

\section{Evaluation and comparison of the obtained data}

The following chart 3 shows the speeds at the beginning of fully braking deceleration, calculated average values for fully braking deceleration time and the data about time and distance the vehicle passed during this section, having various speeds.

Table 3. All experiment results were obtained by XL Meter ${ }^{\mathrm{TM}}$ Pro device and processed by XL Vision ${ }^{\mathrm{TM}}$ Pro freeware

\begin{tabular}{|c|c|c|c|c|c|}
\hline \multirow{2}{*}{ Measurement no. } & \multicolumn{5}{|c|}{ Obtained data } \\
\cline { 2 - 6 } & $\mathbf{V}\left[\mathbf{k m} \cdot \mathbf{h}^{-\mathbf{1}}\right]$ & $\mathbf{v}\left[\mathbf{m . s}^{-\mathbf{1}}\right]$ & $\mathbf{s}[\mathbf{m}]$ & $\mathbf{B}\left[\mathbf{m . s}^{-\mathbf{2}}\right]$ & $\mathbf{t}[\mathbf{s}]$ \\
\hline 7 & 96.80 & 26.89 & 50.10 & 7.93 & 3.53 \\
\hline 6 & 84.96 & 23.60 & 39.29 & 8.03 & 3.13 \\
\hline 5 & 79.51 & 22.09 & 33.07 & 7.89 & 2.91 \\
\hline 4 & 59.01 & 16.39 & 18.43 & 7.92 & 2.13 \\
\hline 3 & 56.41 & 15.67 & 16.75 & 8.22 & 2.02 \\
\hline 2 & 41.66 & 11.57 & 9.35 & 7.71 & 1.56 \\
\hline 1 & 20.89 & 5.80 & 2.52 & 8.08 & 0.84 \\
\hline
\end{tabular}

Summary of mean fully developed deceleration by XL Meter ${ }^{\mathrm{TM}}$ Pro:

Obtained values

- maximum braking deceleration XL Meter ${ }^{\mathrm{TM}}$ Pro: $8.22 \mathrm{~m} . \mathrm{s}^{-2}$ (trial 3),

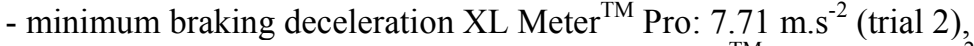

- average magnitude braking deceleration XL Meter ${ }^{\mathrm{TM}}$ Pro: $7.97 \mathrm{~m} . \mathrm{s}^{-2}$,

- standard deviation of braking deceleration XL Meter ${ }^{\mathrm{TM}}$ Pro: 0.149 m.s ${ }^{-2}$.

Table 4. Experiments resuls processed by the program Tracker, fixed point at the end of the front bumper

\begin{tabular}{|c|c|c|c|c|c|}
\hline \multirow{2}{*}{ Measurement no. } & \multicolumn{5}{|c|}{ Obtained data } \\
\cline { 2 - 6 } & $\mathbf{V}\left[\mathbf{k m} \cdot \mathbf{h}^{\mathbf{- 1}} \mathbf{]}\right.$ & $\mathbf{v}\left[\mathbf{m} \cdot \mathbf{s}^{\mathbf{- 1}} \mathbf{]}\right.$ & $\mathbf{s}[\mathbf{m}]$ & $\mathbf{b}\left[\mathbf{m . s}^{-\mathbf{2}}\right]$ & $\mathbf{t}[\mathbf{s}]$ \\
\hline 7 & 83.88 & 23.30 & 40.40 & 7.88 & 3.53 \\
\hline 6 & 78.12 & 21.70 & 34.40 & 8.02 & 3.07 \\
\hline 5 & 73.80 & 20.50 & 30.40 & 7.80 & 2.87 \\
\hline 4 & 58.68 & 16.30 & 18.10 & 7.56 & 2.16 \\
\hline 3 & 55.80 & 15.50 & 15.01 & 7.73 & 2.01 \\
\hline 2 & 39.78 & 11.05 & 8.39 & 7.37 & 1.53 \\
\hline 1 & 18.11 & 5.03 & 2.56 & 7.36 & 0.86 \\
\hline
\end{tabular}

Summary of mean fully developed deceleration by SW Tracker:

\section{Obtained values}

- maximum braking deceleration by SW Tracker: $8.02 \mathrm{~m} . \mathrm{s}^{-2}$ (trial 6),

- minimum braking deceleration by SW Tracker: $7.36 \mathrm{~m} . \mathrm{s}^{-2}$ (trial 1), 
- average magnitude braking deceleration by SW Tracker: $7.67 \mathrm{~m} . \mathrm{s}^{-2}$,

- standard deviation of braking deceleration by SW Tracker: $0.236 \mathrm{~m} . \mathrm{s}^{-2}$.

Figure 10, taken from the program Tracker, plots the evaluation of the course of dependence $v_{x}(t)$ in the real experiment no. 6 . The braking time regarding the fixed point at the end of the rear bumper was of $3.07 \mathrm{~s}$. So the deceleration regarding this fixed point was of $8.02 \mathrm{~m} / \mathrm{s}^{2}$. The braking distance as well as the initial speed show higher deviation compared to XL Vision ${ }^{\mathrm{TM}}$ Pro freeware due to recording problems at a high speed. The braking distance was of $34.4 \mathrm{~m}$ and the initial speed for the given fixed point was of $78.12 \mathrm{~km} / \mathrm{h}$.

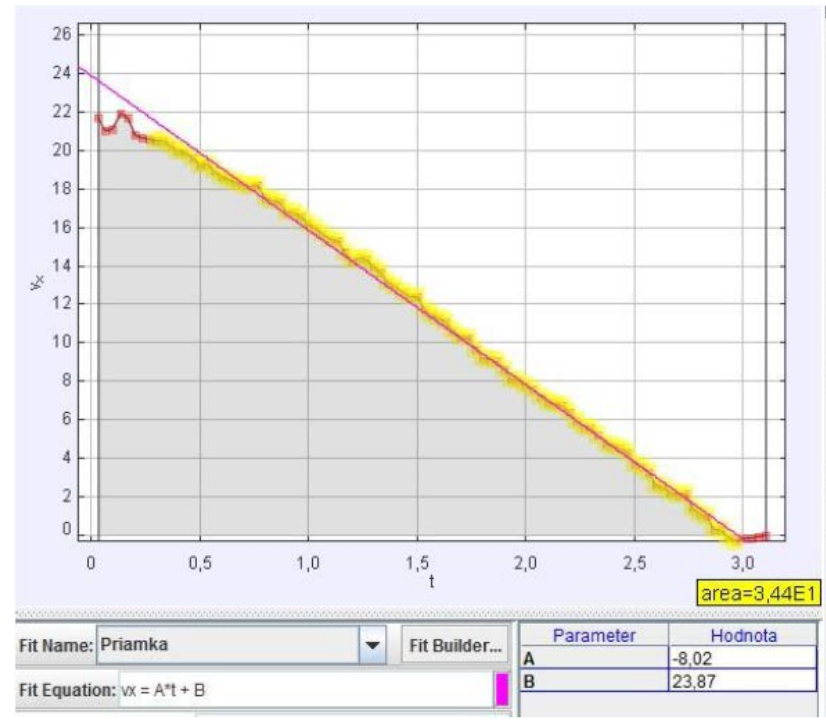

Figure 10. Calculation of deceleration and braking distance in the program Tracker (experiment no. 6)

\section{Comparison of $\mathrm{v}_{\mathbf{x}}-\mathrm{s}$ dependence}

We decided to use the ,braking distance - initial speed" dependence for the final comparison of the obtained data (Fig. 11). The red curve represents the course of the results obtained by XL Meter ${ }^{\mathrm{TM}}$ Pro. The green one represents those results obtained by the video analysis processed by the program Tracker.

Each curve is described by the regression equation. Variable y equals to the 2 nd order polynomial regression. Variable $\mathrm{R}^{2}$ shows the equation of the regression reliability. The value is in both cases extremely high what verifies correctness of the chosen regression type. Both curves are almost of the same course which proves both methods are suitable to be used.

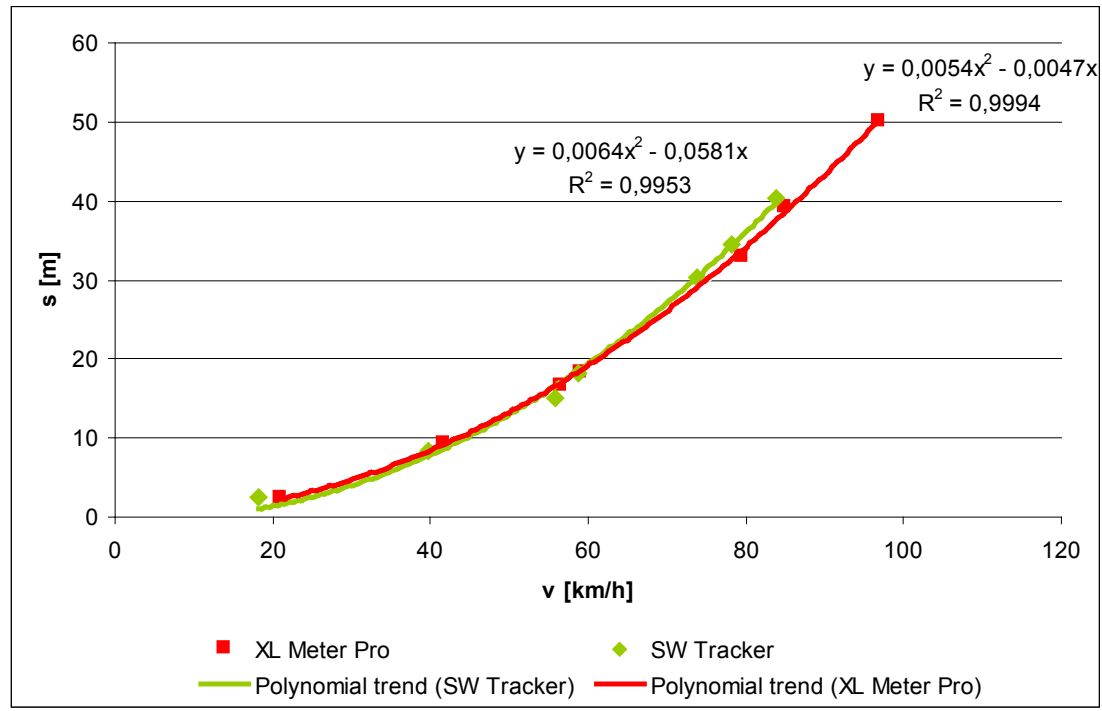

Figure 11. Comparison of the data obtained by SW XL Vision ${ }^{\mathrm{TM}}$ Pro and SW Tracker 
The factor of sliding friction between the asphalt and the car tires was calculated from the graph parameters on the basis of the previous relationship and the relationship of $b=g \mu$; its value was of 0.61 for the Tracker and 0.73 for the XL Meter ${ }^{\mathrm{TM}}$ Pro.

\section{Conclusion}

Our experiment consisted of 7 deceleration measurements with the sampling rate of 200 data per second. The obtained data comparison shows us that the results processed by the program Tracker correspond with the results processed by XL Vision ${ }^{\mathrm{TM}}$ Pro freeware, the accompanying decelerometer software.

The method of video analysis is not to be a substitute for decelerograph; it is, however, an alternative that brings certain pros and cons.

First of all, the use of decelerometer is user-friendlier. It is sufficient to install the measurement device in the vehicle, to calibrate it and to activate it (switch on mode) just before the drive. The device starts automatic data recording within 40 seconds. After measurements are over, it is only necessary to connect it to the PC and to obtain all the numerical and graphical data by means of XL Vision ${ }^{\mathrm{TM}}$ Pro freeware.

The method of video analysis requires study of instruction on how to use the evaluation software, in particular the program Tracker. The principle is not very difficult. Another disadvantage of this method is that the accuracy of the results directly depends on more factors such as: camera quality, a vehicles' contrast with the surroundings, or good weather conditions. The huge advantage of this method is its economic efficiency: measurement can be carried out by any camera, e.g. by todays wide-spread smartphone technology, so a user does not have to buy expensive specialized equipment in case he/she needs to carry out a single measurement, or if he/she owns a high-quality camera, that may be used for the measuremet purposes. (Hockicko, P., Trpišová, B., 2013).

When assessing which device should be preferred, professionals recommend the XL Meter ${ }^{\mathrm{TM}}$ Pro due to its size and installation requirements; however, the program Tracker is a freeware and it provides us with the results comparable with those by XL Meter ${ }^{\mathrm{TM}}$ Pro so the teachers of physics would probably choose this option.

\section{Acknowledgements}

This contribution is the result of the project implementation:

Centre of excellence for systems and services of intelligent transport II, ITMS 26220120050 supported by the Research \& Development Operational Programme funded by the ERDF.
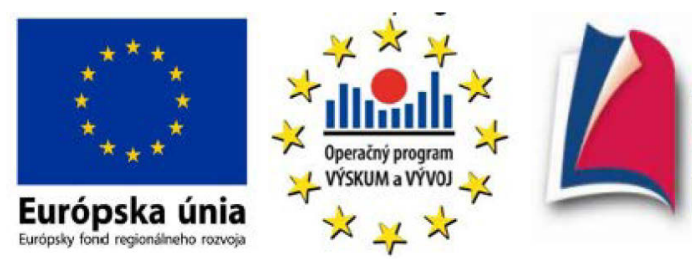

Agentúra

Ministerstva školstva, vedy, výskumu a športu SR pre štrukturálne fondy EÚ

"We support research activities in Slovakia / Project is co-financed by the EU [Podporujeme výskumné aktivity na Slovensku/Projekt je spolufinancovaný zo zdrojov EÚ] "

\section{References}

1. Hockicko, P., Ondruš, J. (2012) Analysis of vehicle stopping distances. In: New trends in physics: NTF 2012: proceedings of the conference, October 11-12, 2012, Brno, Czech Republic. - Brno: University of Technology, 2012, pp. 214-217, ISBN 978-80-214-4594-9.

2. Hockicko, P., Trpišová, B. (2013) Are students' conceptions about automobile braking distances correct? In: Engineering Education Fast Forward 1973 - 2013: proceedings of the 41st SEFI annual conference, 16-20 September 2013, Leuven, Belgium. - Brussels: SEFI, ISBN 978-2-87352-004-5.

3. Kolla, E., Kohút, P., Kubjatko, T. (2014) Analysis of pedestrain body movement in pedestrian - MPV collision. In: Automotive safety 2014: problemy bezpeczeństwa w pojazdoch samochodowych. IX international science-technical conference: Rajecké Teplice - Slovakia, 8-10 April 2014. Kielce: Wydawnictwo Politechniki Świętokrzyskiej, pp. 198-208. ISBN 978-83-63792-21-3. 
4. Rievaj, V., Vrábel, J., Hudák, A. (2013) Tire inflation pressure influence on a vehicle stopping distances, In: International Journal of Traffic and Transportation Engineering. Vol. 2, No. 2, pp. 913. ISSN 2325-0062.

5. Šarkan, B. (2013) Diagnostics of road vehicles: instructions for exercises (in Slovak). Zilina: University of Zilina, EDIS, 106 pp, ISBN 978-80-554-0799-9.

6. Handbook of XL Meter ${ }^{\mathrm{TM}}$ Pro

7. http://www.cabrillo.edu/ dbrown/tracker/

8. http://www.inventure.hu/xl_meter_en

9. http://www.inventure.hu/upload/downloads/XLMPLFEN22.pdf

10. http://www.automobile-catalog.com/auta_details1.php

11. http://www.exilim.eu/euro/exilimhighspeed/exfh25/ 